\title{
KONSEP DESAIN PEMBANGKIT LISTRIK TENAGA UAP MEMANFAATKAN SUMBER PANAS BERTEMPERATUR RENDAH DENGAN MEMAKAI SIKLUS RANKINE ORGANIK
}

\author{
Ign. Riyadi Mardiyanto, Dinny Niaty dan Ika Yuliyani \\ Jurusan Teknik Konversi Energi Politeknik Negeri Bandung \\ Emal: Ig_R_M@yahoo.com
}

\begin{abstract}
Abstrak
Siklus Rankine Organik (ORC) menggunakan dua refrigeran organik yakni R22 dan R134a dapat digunakan untuk mengkonversi panas dari sumber air panas bersuhu sekitar $80^{\circ} \mathrm{C}$. Menggunakan air pendingin dengan temperatur $18^{\circ} \mathrm{C}$, dengan $R 22$ didapat efisiensi siklus sekitar $5 \%$. Sedangkan jika menggunakan R134a akan didapat efisiensi siklus sekitar $6 \%$. Untuk membangkitkan daya listrik sekitar $3 \mathrm{~kW}$ dapat menggunakan ORC dengan refrigerant tersebutyang membutuhkan laju aliran air panas bersuhu $80^{\circ} \mathrm{C}$ sebesar 0.8 liter per detik.
\end{abstract}

Kata Kunci: pembangkit listrik tenaga uap (PLTU), siklus rankine organik, refigeran $R 22$ dan R134a

\section{PENDAHULUAN}

Kebutuhan energi merupakan sesuatu yang tidak dapat terpisahkan dari kehidupan manusia saat ini, energi mempunyai peranan penting dalam kehidupan sosial, ekonomi dan lingkungan yang berkelanjutan. Seiring dengan kemajuan teknologi ternyata makin banyak energi fosil yang digunakan oleh pembangkit listrik seperti PLTU maupun PLTGU untuk menghasilkan energi listrik yang akan didistribusikan kepada masyarakat. Peningkatan permintaan energi yang disebabkan oleh pertumbuhan populasi penduduk dan menipisnya sumber cadangan minyak dunia dari bahan bakar fosil memberikan tekanan kepada setiap negara untuk segera memproduksi dan menggunakan energi terbarukan.

Sebagai daerah vulkanik, wilayah Indonesia sebagian besar kaya akan sumber energi panas bumi. Jalur gunung berapi membentang di Indonesia dari ujung Pulau Sumatera sepanjang Pulau Jawa, Bali, NTT, NTB menuju Kepulauan Banda, Halmahera, dan Pulau Sulawesi. Energi panas bumi dikonversikan menjadi listrik dengan menggunakan siklus termodinamika. Siklus termodinamika adalah kumpulan berbagai proses termodinamika yang didasarkan pada hukum kekekalan energi. Dengan menggunakanpanas bumi dapat dirubah menjadi jenis energi lain.

Di bidang energi panas bumi, digunakan beberapa jenis siklus termodinamika, misalnya siklus Kalina, siklus Rankine, siklus Carnot dan lain- lain. Siklus Rankine adalah siklus termodinamika yang mengubah panas menjadi kerja dengan memanfaatkan perubahan fasa fluida yakni dari fasa cair ke fasa uap/gas.

\section{Konsep Siklus Rankine}

Panas dari sumber panas digunakan untuk menguapkan cairan yang bertekanan tertentu pada ruang penguap (boiler/heat exchanger), kemudian uap ini digunakan untuk menggerakkan media mekanik (turbine/ekpander) sehingga didapatkan kerja mekanik berupa putaran rotor turbine. Karena energi pada fasa uap telah dipakai untuk kerja mekanik maka berakibat pada turunnya tekanan dan temperatur. Selanjutnya uap yang telah turun tekanan dan temperaturnya diubah fasanya dengan menggunakan pengambil panas sisa atau kondensor sehingga menjadi berfasa cair. Cairan ini kemudian dipompakan ke boiler yang mempunyai tekanan tertentu dan diberikan panas sampai menjadi uap kembali, sedemikian hingga siklus termodinamika menjadi sempurna dan dapat diulang terus menerus dan dirasakan sebagai kerja kontinyu pada rotor turbin.

\section{Konsep Siklus Rankine Organik}

Pada siklus Rankine, cairan yang digunakan adalah air. Seperti halnya pada Siklus Rankine, 
Siklus Rankine Organik juga mengubah panas menjadi kerja, hanya saja fluida yang digunakan adalah fluida organik/refrigerant.Penggunaan jenis fluida organik ini diharapkan dapat menurunkan temperatur dari sumber panas untuk penguapan fluida yakni karena rendahnya titik didih dari jenis fluida tersebut. Karena alasan inilah Siklus Rankine Organik cocok digunakan pada pembangkitanenergi listrik tenaga panas bumi dengan temperatur yang rendah yakni antara $80^{\circ} \mathrm{Csampai} 200^{\circ} \mathrm{C}$.

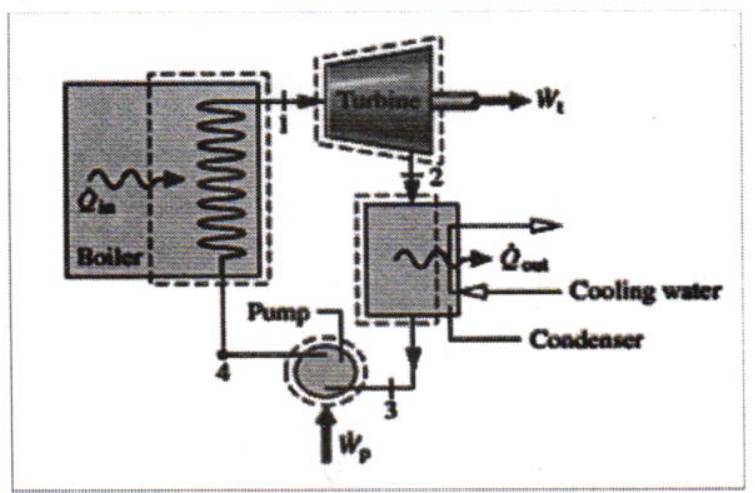

Gambar 1. Prinsip Kerja Siklus Rankine

Seperti halnya siklus Rankine; siklus Rankine organik secara sederhana dapat dibangun menggunakan empat komponen utama yakni heat exchanger, turbin, kondensor dan pompa dengan pipa-pipa penghubung antara komponen.Satu siklus terjadi, apabila fluida kerja telah berubah dari cair dengan tekanan tertentu mejadi uap pada heat exchanger kemudian fluida menggerakkan rotor turbin.Setelah melewati turbin dikondensasi oleh kondensor, dan dipompakan kembali ke boiler oleh pompa pengumpan.

\section{Konsep Desain Siklus Ran kine Organik}

Pada siklus Rankine organik, digunakan fluida kerja bahan organik/refrigerant yang pada tekanan tertentu dengan panas tertentu akan berubah dari cair menjadi gas. Tetapi pada kondisi temperatur ruangan, ternyata bahan organik tidak kondensasi.Untuk terkondensasi pada temperatur lingkungan maka tekanan gas refrigerant organik tersebut harus mempunyai tekanan jauh diatas atmosfer.
Jadi dapat dikatakan bahwa pada tekanan atmofer dan temperatur sekitar $20^{\circ} \mathrm{C}$ maka refrigerant telah berada pada fasa uap.Tabel 1 berikut adalah contoh titik kritis dan titik didih dua refrigerant organik yang berbeda.Terlihat bahwa pada kondisi tekanan $1 \mathrm{~atm}$, maka titik didihnya adalah dibawah $0^{\circ} \mathrm{C}$. Jadi temperatur pengembunan pada tekanan 1 atm akan berada pada temperatur dibawah nilai tersebut. Dengan demikian dapat dikatakan bahwa untuk memenuhi siklus Rankine,kondensasi fluida organik tersebut harus pada tekanan jauh diatas $1 \mathrm{~atm}$. Jadi titik penting dari konsep desain siklus Rankine Organik ini salah satunya adalah pembuatan siklus dengan tekanan kerja yang semuanya jauh diatas tekanan atmosfer.

Tabel 1. Contoh Karakteristik Fluida Organik

\begin{tabular}{|c|c|c|c|c|}
\hline \multirow[b]{2}{*}{ No } & \multirow[b]{2}{*}{ Fluida } & \multicolumn{2}{|c|}{ Titik Kritis } & \multirow{2}{*}{$\begin{array}{l}\text { Titik Didih } \\
\text { pada latm } \\
\left.{ }^{\circ} \mathrm{C}\right)\end{array}$} \\
\hline & & $\begin{array}{l}\text { Temp. } \\
\left({ }^{\circ} \mathrm{C}\right)\end{array}$ & $\begin{array}{l}\text { Tek. } \\
\text { (MPa) }\end{array}$ & \\
\hline 1. & R22 & 96.1 & 4,99 & -41 \\
\hline 2. & R134a & 101.2 & 4.06 & -25 \\
\hline
\end{tabular}

Selanjutnya, dengan menggunakan diagram tekanan entalphi, maka akan dapat digambarkan perkiraan tekanan kondensasi yang harus disiapkan pada fluida kerja yang melalui kondensor sedemikian sehingga fluida kerja dapat terkondensasi. Berikut adalah gambaran tekanan-entalphi dari fluida kerja R22 yang akan disimulasikan lebih lanjut.Kemudian juga dapat diidentifikasi tekanan dan temperatur penguapan.Untuk gambaran siklus kerja dengan me makai grafik tekanan-entalphi ini perlu identifikasi data potensi energi di lapangan.

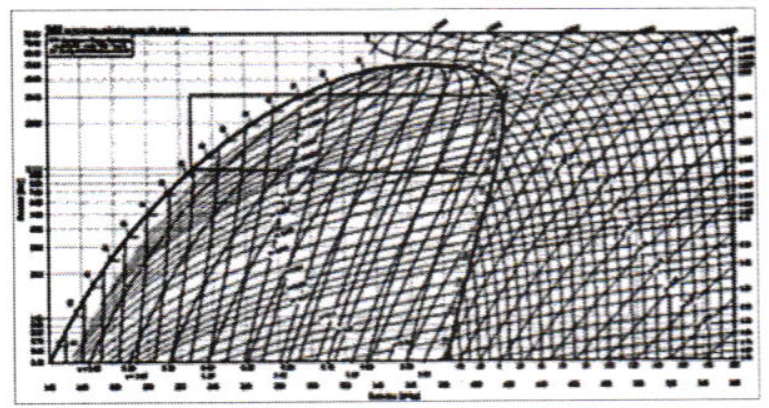

Gambar 2. Grafik Tekanan-Entalphi dari R22

Misal, diketahui dari hasil pengukuran suatu tempat di Gunung Galunggung Kabupaten Tasikmalaya, diketahui datanya adalah sebagai berikut. 
Tabel 2 Data Pengukuran Lapangan

\begin{tabular}{|c|c|c|c|c|c|}
\hline \multirow{2}{*}{ No. } & \multicolumn{2}{|c|}{ Air Panas } & \multicolumn{3}{c|}{ Air Dingin } \\
\cline { 2 - 6 } & $\begin{array}{c}\text { Flow } \\
(\mathrm{lt} / \mathrm{s})\end{array}$ & $\begin{array}{c}\text { Temp. } \\
\left({ }^{\circ} \mathrm{C}\right)\end{array}$ & $\begin{array}{c}\text { Temp } \\
\left({ }^{\circ} \mathrm{C}\right)\end{array}$ & $\begin{array}{c}\text { Tekanan } \\
(\mathrm{atm})\end{array}$ & $\begin{array}{c}\text { Kelembaban } \\
(\%)\end{array}$ \\
\hline 1. & $>10$ & 80 & 18 & 1 & 75 \\
\hline
\end{tabular}

Pump. Pompa dimaksudkan untuk menaikkan tekanan pada fluida kerja sehingga mempunyai tekanan yang cukup tinggi sebelum fuida kerja tersebut diubah menjadi fasa uap pada boiler/heat exchanger. Dengan kondisi air panas yang akan dimanfaatkan untuk pembangkit listrik adalah sekitar $80{ }^{\circ} \mathrm{C}$, maka tekanan fluida kerja R22 adalah sekitar 3 lbar. Dengan memilih tekanan pompa misalnya sebesar 32 bar, maka fluida kerja akan dapat diuapkan dengan heat exchanger/boiler dengan temperatur masukan sebesar $80^{\circ} \mathrm{C}$, seperti data lapangan di atas.

Fluida kerja dalam bentuk cair yang berasal dari kondensor akan dipompakan ke dalam heat exchanger yang bertekanan lebih tinggi. Kesetimbangan laju massa dan energi persamaan sederhananya seperti berikut ini.

$$
\frac{\dot{W}_{\mathrm{p}}}{\dot{m}}=h_{4}-h_{3}
$$

Heat exchanger/boiler.FLuida kerja dimasukkan kedalam heat exchanger dan dengan sumber panas yang melalui heat exchanger sampai fluida kerja menjadi uap.

Pada boiler terjadi tiga keadaan yakni, pada keadaan pertama adalah keadaan pemanasan fluida kerja pada tekanan sesuai dengan tekanan keluaran pompa sampai panas sesuai dengan panas penguapan.Kemudian keadaan kedua adalah keadaan perubahan fluida kerja dari keadaan cair menjadi uap pada tekanan tersebut.Selanjutnya keadaan ketiga adalah uap pada boiler dipanaskan lebih lanjut yang menjadikan uap menjadi semakin panas.Uap fluida kerja dengan tekanan sekitar 31 bar dan temperatur sekirar $80^{\circ} \mathrm{C}$ ini selanjutnya dapat dipakai untuk memutar turbin uap/ekspander.Persamaan sederhana untuk heat exchanger tersebut adalah sebagai berikut.

$$
\frac{\dot{Q}_{\text {in }}}{\dot{m}}=h_{1}-h_{4}
$$

Turbine/Ekspander. Uap kerja dari heat exchanger pada kondisi 1 , uap dengan tekanan sekitar 30 bar dengan temperatur $76^{\circ} \mathrm{C}$ akan berekspansi melalui turbin/ekspander untuk menghasilkan kerja mekanik berupa putaran rotor ekspander, dan kemudian disalurkan ke kondensor pada kondisi 2. Pada kondisi uap keluar dari turbin, tekanan dan temperatur menjadi relatif rendah yakni tekanan sekitar 9 bar dengan temperatur sekitar $20{ }^{\circ} \mathrm{C}$. Dengan mengabaikan perpindahan panas di sekeliling turbin, kesetimbangan laju energi dan massa disekitar turbin menjadi:

$$
\frac{\dot{W}_{t}}{\dot{m}}=h_{1}-h_{2}
$$

Condenser. Dari Gambar 2 dan Tabel 2 di atas, dapat diketahui bahwa untuk mengambil panas sisa fluida kerja R22 sehingga fluida kerja menjadi pada temperatur di sekitar $20^{\circ} \mathrm{C}$ maka tekanan dari fluida kerja adalah sekitar 9,5 bar. Artinya, jika kita menggunakan air lingkungan untuk membawa panas yang berasal dari fluida kerja melalui komponen kondesor, maka tekanan fluida kerja haruslah sama dengan atau diatas 9 bar, yakni agar terjadi perpindahan panas dari fluida kerja organik tersebut ke air pembawa panas, misal dengan temperatur antara $18^{\circ} \mathrm{Csampai} 20^{\circ} \mathrm{C}$, sehingga fluida kerja menjadi terkondensasi dan menjadi cair kembali. Dalam kondensor terjadi perpindahan panas.Uap terkondensasi dan temperaturcooler meningkat. Keseimbangan laju massa dan energi adalah:

$$
\frac{\dot{Q}_{\text {out }}}{\dot{m}}=h_{2}-h_{3}
$$

Parameter kinerja.Efisiensi termal mengukur seberapa banyak energi yang masuk ke dalam fluida kerja melalui yang dikonversi menjadi keluaran kerja. Efisiensi termal dari siklus adalah:

$$
\eta_{\text {therm }}=\frac{\dot{W}_{\text {turbine }}-\dot{W}_{\text {pump }}}{\dot{Q}_{\text {in }}}
$$

Pemilihan fluida kerja adalah kunci penting dalam siklus Rankine organik.Karena temperatur yang rendah, ketidak-efisienan perpindahan panas sangat merugikan.Ketidak- 
efisienan ini tergantung pada karakteristik temodinamika fluida dan kondisi saat beroperasi.Pemilihan fluida kerja yang akan digunakan ini berdasarkan pada besarnya entalpi dan rendahnya titik didih fluida. Selain itu ketersediaan dan harga fluida pun menjadi pertimbangan dalam pemilihan fluida kerja ini.

\section{HASIL DAN DISKUSI}

Pada pengujian ini digunakandua jenis fluida organik yang digunakan fluida kerja yakni R22 dan R134a, dan berikut data inputnya dan andaian efisiensi peralatan pengkonversi.

Table 3 Data input simulasi

\begin{tabular}{|c|c|c|c|c|}
\hline No. & $\begin{array}{c}\text { Fluida } \\
\text { yang } \\
\text { Digunakan }\end{array}$ & $\begin{array}{c}\mathrm{P}_{\text {in }} \\
\text { Turbin } \\
\text { (bar) }\end{array}$ & $\begin{array}{c}\mathrm{T}_{\text {in }} \\
\text { Turbin } \\
\left({ }^{\circ} \mathrm{C}\right)\end{array}$ & $\begin{array}{c}\mathrm{P}_{\text {out }} \\
\text { Kondensor } \\
\text { (bar) }\end{array}$ \\
\hline 1 & R22 & 31.57 & 76 & 9.5 \\
\hline 2 & R134a & 21 & 76 & 6 \\
\hline
\end{tabular}

Table lanjutan 3

\begin{tabular}{|c|c|c|c|c|c|}
\hline $\begin{array}{c}\eta \text { Pompa4 } \\
(\%)\end{array}$ & $\begin{array}{c}\eta \\
\text { Generator } \\
(\%)\end{array}$ & $\begin{array}{c}\eta \\
\text { Turbin } \\
(\%)\end{array}$ & $\begin{array}{c}\text { Tin } \\
\text { Air } \\
\left({ }^{0} \mathrm{C}\right)\end{array}$ & $\begin{array}{c}\text { Tout } \\
\text { Air } \\
\left.{ }^{0} \mathrm{C}\right)\end{array}$ & $\begin{array}{c}\text { Output } \\
\text { Generator } \\
(\mathrm{kW})\end{array}$ \\
\hline 77 & 95 & 65 & 18 & 20 & 5 \\
\hline 77 & 95 & 65 & 18 & 20 & 5 \\
\hline
\end{tabular}

Untuk menghasilkan daya keluaran $5 \mathrm{~kW}$ seperti direncanakan pada table di atas, dengan data-data masukan seperti tabel 3 di atas, didapatkan nilai nilai hasil simulasi seperti tabel 4 di bawah ini.

Table 4 Data Hasil Simulasi

\begin{tabular}{|c|c|c|c|c|c|}
\hline No. & $\begin{array}{c}\text { Laju } \\
\text { Fluida } \\
\text { kerja } \\
(\mathrm{kg} / \mathrm{s})\end{array}$ & $\begin{array}{c}\text { Laju } \\
\text { Air } \\
\text { panas } \\
(\mathrm{lt} / \mathrm{s})\end{array}$ & $\begin{array}{c}\text { Daya } \\
\text { Pompa } \\
\text { fluida } \\
(\mathrm{kW})\end{array}$ & $\begin{array}{c}\text { Daya } \\
\text { pompa } \\
\text { pendingin } \\
(\mathrm{kW})\end{array}$ & $\begin{array}{c}\text { Laju Air } \\
\text { Pendingin } \\
(\mathrm{lt} / \mathrm{s})\end{array}$ \\
\hline 1 & 0,39 & 0,69 & 1,77 & 0.3 & 6.3 \\
\hline 2 & 0,41 & 0,82 & 1,25 & 0.37 & 7,78 \\
\hline
\end{tabular}

Tabel 5 Tabel Data Entalpi Hasil Perhitungan Teoritis

\begin{tabular}{|c|c|c|c|c|c|}
\hline No. & $\begin{array}{c}\text { Fluida } \\
\text { yang } \\
\text { Digunakan }\end{array}$ & $\begin{array}{c}\mathrm{h}_{1} \\
(\mathrm{~kJ} / \mathrm{kg})\end{array}$ & $\begin{array}{c}\mathrm{h}_{2} \\
(\mathrm{~kJ} / \mathrm{kg})\end{array}$ & $\begin{array}{c}\mathrm{h}_{3} \\
(\mathrm{~kJ} / \mathrm{kg})\end{array}$ & $\begin{array}{c}\mathrm{h}_{4} \\
(\mathrm{~kJ} / \mathrm{kg})\end{array}$ \\
\hline 1. & $\mathrm{R} 22$ & 423 & 410 & 228 & 229 \\
\hline 3. & R134a & 430 & 414 & 230 & 232 \\
\hline
\end{tabular}

Perhitungan efisiensi siklus teoritis, hanya dimasukkan penggunaan pompa tekanan fluida kerja. Untuk efisiensi sistem pada simulasi, dihitung pula daya yang digunakan untuk pompa pendingin.

Tabel 6. Tabel Perbandingan Nilai Efisiensi HasilSimulasi DanPerhitungan Teoritis

\begin{tabular}{|c|c|c|c|}
\hline No. & $\begin{array}{c}\text { Fluida } \\
\text { Kerja }\end{array}$ & $\begin{array}{c}\text { Simulasi } \\
\text { (efisiensi } \\
\text { sistem, \%) }\end{array}$ & $\begin{array}{c}\text { Teoritis } \\
\text { (efisiensi } \\
\text { thermal, \%) }\end{array}$ \\
\hline 1. & R22 & 5.1 & 6.2 \\
\hline 2. & R134a & 5.9 & 7.1 \\
\hline
\end{tabular}

Tabel 6 diatas memperlihatkan perbandingan antara data hasil simulasi perangkat lunak dengan data hasil perhitungan secara teoritis. Pada Tabel 6 tersebut,ditunjukkan bahwa baik dari hasil simulasi maupun data hasil perhitungan teoritis nilai efisiensinya sedikit berbeda. Seperti halnya pada siklus yang menggunakan R22 sebagai fluida kerjanya dapat kita lihat bahwa efisiensi yang dihasilkan siklus hasil simulasi program nilai efisiensinya sebesar $5,1 \%$, dan nilai efisiensi hasil perhitungan secara teoritis sebesar $6,2 \%$.Jika dibandingkan, dari kedua fluida kerja yang digunakan yakni R22 dan R134a, yang memiliki nilai efisiensi paling besar adalah R134a yaitu sebesar 5,9\% hasil simulasi dan $7,1 \%$ hasil perhitungan teoritis.

Pada tekanan 31,57 bar dan temperatur $76^{\circ}$ Crefrigeran R22 sudah berubah fasa menjadi uap jenuh,untuk kemudian refrigeran ini digunakan memutar ekspander. Keluaran dari ekspander agar dapat diambil energinya sehingga refrigeran mengembun adalah pada tekanan 9,5 dan temperatur $20^{\circ} \mathrm{C}$, karena temperatur pendingin adalah $18^{\circ} \mathrm{C}$. Hasil kondensasi ini selanjutnya ditekan heat exchanger untuk selanjutnya ditambah energinya dengan cara memberi panas dengan fluida panas dari sumber air panas. Dengan temperatur mula-mula sebesar $20^{\circ} \mathrm{C}^{\prime}$ kemudian refrigeran sebagai fluida kerja ditambah energinya sehingga suhunya menjadi $76{ }^{\circ} \mathrm{C}$ dengan tekanan 31,57 bar, maka fasa fluida kerja R22 menjadi uap kering yang siap digunakan untuk memutar ekspander. Sehingga secara keseluruhan siklus Rankine Organik menjadi terpenuhi. Hasil perhitungan teoritis maupun simulasi untuk efisiensi dari fluida kerja ini adalah sekitar $5 \%$ seperti telah disebutkan di atas. 


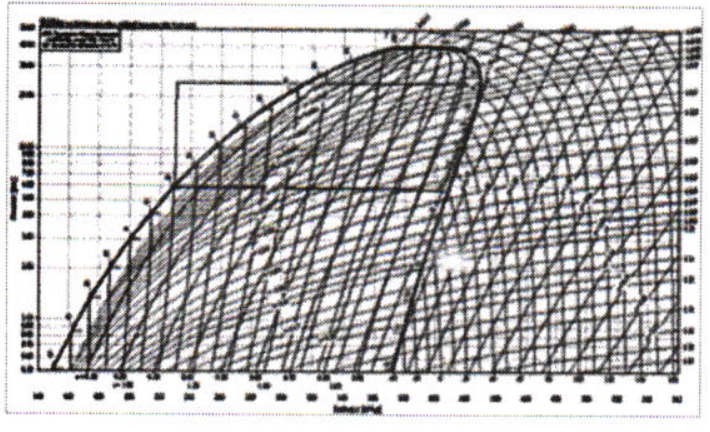

Gambar 3 Diagram pressure-entalphydariR134a

Dalam proses ini tekanan dan temperatur refrigeran turun. Untuk refrigeran R134a perubahan fasa menjadi uap kering terjadi pada saat suhu refrigerant mencapai $76^{\circ} \mathrm{C}$ dengan tekanan 21 bar. Dan uap tersebut kemudian dikondensasi pada temperatur $20^{\circ} \mathrm{C}$ sehingga tekanan fluida uap terkondensasi menjadi sekitar6 bar.

\section{KENDALA PENERAPAN}

Diketahui bahwa, tekanan output turbin untuk siklus rankine organic ini,di atas atmosfer. Dengan tingginya tekanan ini maka akan perlu dipikirkan pembuatan seal pada turbin maupun pompa agar fluida kerja tidak bocor ke atmosfer melalui sela-sela poros rotor dan stator turbin maupun pompa tersebut.

\section{KESIMPULAN}

Setelah dliakukan identifikasi lapangan di sumber air panas yang berlokasi di Gunung GalunggungTasikmalaya, kemudian dilanjutkan dengan perancangan model siklus Rankine organik yang diuji dan kemudian melakukan simulasi untuk dua jenis fluida yakni R22 dan R134apada suhu sumber sebesar $80{ }^{\circ} \mathrm{C}$, maka fluida yang memiliki nilai efisiensi yang lebih baik adalah R134adengan nilai 5,9\%.

Dari hasil pengujian ini dapat dikatakan bahwa sumber air panas tersebut di atas, berpotensi untuk dijadikan pembangkit listrik skala kecil. Namun untuk merealisasikannya diperlukan studi lebih lanjut dengan melakukan detail desain dan pembuatan alatnya dengan memperhatikan kendala tekanan operasional siklus.

\section{DAFTAR PUSTAKA}

Aminuddin, Antonius Bintarto Ekoprasetyo. 2005. Teknik ORC untuk Ekstraksi Energi dari Sumber Energi Potensi Rendah.http://www.p3 tkebt.esdm.go.id Ariyanto, Sudi. 2004. Energi Terbarukan Belum Dimanfaatkan Secara Sempurna. http://id.wikipedia.org/wiki/Energi Terbarukan

Batton, Bill. 2000. Mesin Siklus Rankine Organik untuk Solar Power(terjemahan).

http://www.nrel.gov/csp/troughnet/pdfs/ batton orc.pdf.

Bronicki, LY. 1984.Dua puluh Lima Tahun Pengalaman dengan Rankine Organik Cairan di Turbomachinery. http:// id.wikipedia.org/wiki/Siklus Rankine Organik.

Engle, David. 2008. Dari Limbah Panas Untuk Energi. (terjemahan). http://ormat data/marcom/ormat

Geankoplis, J Cristie. 1983. Transport Process and Unit Operations $2^{\text {nd }}$ Edition. USA : Allyn and Bacon.

Kulshrestha, S.K. 1989. Termodinamika Terpakai, Teknik Uap dan Panas (Penerjemah: Budiardjo, I Made Kartika D, Budiarso). Jakarta, Universitas Indonesia.

Moran, Michael J dan Howard N. Shapiro. 2006. Fundamentals of Engineering Thermodynamics $5^{\text {th }}$ Edition. England :John Wiley \& Sons, Inc. 